
Revue Revue de l'histoire des religions
de Ihistoire des religions
$1 \mid 2012$
Judaïsme / christianisme : syncrétismes, antinomies, dissonances

\title{
Marcello MASSENZIO, Le Juif errant ou l'art de survivre
}

Paris, Éditions du Cerf, « Les conférences de l'École Pratique des Hautes Études », 2010, 141 p., illustrations, 19 cm, 15 €, ISBN 978-2-204-09236-4

\section{Dan Arbib}

\section{OpenEdition}

\section{Journals}

Édition électronique

URL : http://journals.openedition.org/rhr/7880

DOI : $10.4000 /$ rhr.7880

ISSN : 2105-2573

Éditeur

Armand Colin

Édition imprimée

Date de publication : 1 mars 2012

Pagination : 153-154

ISSN : 0035-1423

Référence électronique

Dan Arbib, "Marcello mASSENzIo, Le Juif errant ou l'art de survivre », Revue de l'histoire des religions [En

ligne], 1 | 2012, mis en ligne le 04 avril 2012, consulté le 22 septembre 2020. URL : http:// journals.openedition.org/rhr/7880 ; DOI : https://doi.org/10.4000/rhr.7880

Ce document a été généré automatiquement le 22 septembre 2020.

Tous droits réservés 


\title{
Marcello MASSENZIO, Le Juif errant ou l'art de survivre
}

\author{
Paris, Éditions du Cerf, « Les conférences de l'École Pratique des Hautes \\ Études ", 2010, 141 p., illustrations, 19 cm, 15 €, ISBN 978-2-204-09236-4
}

\section{Dan Arbib}

\section{RÉFÉRENCE}

Marcello MASSENZIO, Le Juif errant ou l'art de survivre, Paris, Éditions du Cerf, « Les conférences de l'École Pratique des Hautes Études », 2010, 141 p., illustrations, $19 \mathrm{~cm}$, $15 €$, ISBN 978-2-204-09236-4.

1 Il s'agit là de la reprise de conférences données par M. Massenzio, professeur à l'Université Tor Vergata de Rome, dans le cadre de la chaire d'«Ethnologie religieuse de l'Europe ", de Giordana Charuty, directrice d'études à l'EPHE. L'auteur y poursuit l'importante et originale investigation sur le mythe du Juif errant déjà entamée dans son ouvrage précédent, La Passion selon le Juif errant (Paris, L'Échoppe, 2006). La méthode de cette recherche n'est ni proprement d'histoire de l'art, ni de littérature - quoiqu'elle ait pour objets des œuvres d'art et des textes littéraires - mais celle de l'anthropologie culturelle, pénétrée de l'analyse des mythes de l'anthropologie structurale de LéviStrauss dont l'influence est pleinement revendiquée (p. 18-20). Tachant d'expliciter et d'interpréter non pas toutes, mais quelques variations autour du mythe du Juif - qu'il considère (comme l'expliquait son précédent ouvrage) comme déposé dans la version médiévale de Matthieu Paris (XIII ${ }^{\mathrm{e}}$ siècle) et dans « la version qui a fixé le stéréotype du mythe » (p. 23), la Courte Description et Histoire d'un Juif nommé Ahasvérus (1602) -, l'auteur analyse successivement les reprises de Goethe (chap. I), de Chagall (chap. II), de Wiesel (chap. III), après une magistrale étude introductrice des fresques de la chapelle Scrovegni.

2 On retiendra surtout de cet essai la liberté de ton et la justesse d'interprétation, sur des questions aussi discrètes que fondamentales. L'auteur démasque ainsi avec un réel 
bonheur « le Juif errant » de Wiesel, sous les traits duquel il trouve le très énigmatique «Monsieur Chouchani » (p. 112 sq.), maître de Levinas et de Wiesel, dont il compare les expériences: l'inspiration directrice de Wiesel étant alors saisie au plus près, au confluent d'une tradition longue et d'une inspiration personnelle. Mais davantage: s'intéressant à la reprise juive du mythe, Massenzio touche avec exactitude certains points de divergence entre la construction chrétienne du mythe et sa reprise juive. On notera entre autres la mention $\mathrm{du}$ «sac » dans la reprise par Chagall du mythe : «le détail du sac ne fait pas partie, d'après les données à notre disposition, de l'iconographie traditionnelle du Juif errant; son apparition est donc l'un des reflets de l'appropriation juive du mythe, qui a produit une véritable rupture, plus qu'un changement superficiel de la matrice chrétienne » (p. 64). Alors que chez Goethe, le thème est ambigu, puisque le Juif est à la fois témoin de la Passion et coupable, il devient chez Chagall symbolique d'une souffrance qu'aucune Passion ne peut rédimer, avant d'incarner chez Wiesel la mémoire elle-même qui résiste aux destructions du temps et de la Shoah, « détenteur de l'art de survivre » (p. 130).

Quoiqu'il ne s'agisse pas là, on l'a dit, d'histoire de l'art, on songera souvent à Daniel Arasse (dont Le Détail est explicitement convoqué pour interpréter l'horloge à pendule de La chute de l'ange, de Chagall, p. 71-72), et on se réjouira du cahier d'illustrations grû́ce auquel le lecteur peut avoir «sous les yeux» la grande majorité des œuvres présentées. Plus profondément, ce livre invite à une réflexion sur le statut de l'homme broyé par l'histoire et la violence, les rapports entre profane et sacré, entre création et destin. Bref, un essai savant mais simple et suggestif, portant encore les traces de l'oralité, comme on en redemande.

\section{AUTEURS}

\section{DAN ARBIB}

Fondation Thiers, CNRS. 